\title{
Improvement of Machining Processes: A Case Study
}

\author{
${ }^{1}$ Hakan Gökçe, ${ }^{1}$ Ramazan Yeşilay, ${ }^{* 1}$ Necati Uçak, ${ }^{2}$ Ali Teke and ${ }^{1}$ Adem Çiçek \\ ${ }^{* 1}$ Faculty of Natural Sciences and Engineering, Department of Mechanical Engineering, Ankara Yıldırım Beyazit \\ University, Turkey \\ ${ }^{2}$ Pi Makina Co. Inc., Department of Manufacturing, Turkey
}

\begin{abstract}
In material removal processes, determination of optimal machining strategy is a key factor to increase productivity. This situation is gaining more importance when machining components with complex geometry. The current practice in the determination of machining strategy mostly depends on the experience of the machine operator. However, poorly designed machining processes lead to timeconsuming and costly solutions. Therefore, the improvement of machining processes plays a vital role in terms of machining costs. In this study, the machining process of a boom-body connector (GGG40) of a backhoe loader was improved. Improvements of toolpaths and cutting conditions of 22 different material removal processes were checked through a CAM software. According to the simulation results, the process plan was rearranged. Besides, some enhancements in casting model were conducted to decrease in the number of machining operations. When compared to current practice, a reduction of 55\% in machining time was achieved.
\end{abstract}

Key words: Cutting condition, tool path, machining time, machining order

\section{Introduction}

Machining is a manufacturing process in which a cutting tool is used to obtain desired shape by cut away unwanted segment of material from a workpiece [1]. As well-known, turning, milling, and drilling are the most common machining operations. From 1775 (cannon-boring machine by John Wilkinson) to 1960s (CNC machines), machining has come to a modern stage and it continues to progress with development of new machining technologies and methods [2]. An important goal in the machining also is determination of optimal machining strategy. Optimization of machining processes is very critical in metal cutting industry due to the increasing demand for high quality and low cost products in the market [3]. Therefore, to achieve minimum production costs and time, and maximum production rate, machining operations need to be planned in accordance with optimal machining strategies. In workshop practices, machining parameters are chosen according to machining databases, catalogues, handbooks and/or experience of the operator. However, some aspects such as fixture design, machining order, etc. need to be considered to obtain an optimal process plan of a complex part. Therefore, a large number of studies related to optimization and improvement of machining processes have been recently conducted. Rodriguez-Alabanda et al. [4] investigated the effects of different cutting strategies and cutting parameters on optimization of surface roughness and energy consumption when machining of $\mathrm{Al}-\mathrm{Zn}-\mathrm{Mg}-(\mathrm{Cu})$ alloy. They

*Corresponding author: Necati Uçak. Address: Faculty of Engineering and Natural Sciences, Department of Mechanical Engineering, Ankara Yıldırım Beyazıt University, 06010, Ankara TURKEY. E-mail address: nucak@ybu.edu.tr, Phone: +903129062333. 
reported that it is possible to reduce energy consumption of $40 \%$ and improve surface quality of $70 \%$ with proper selection of cutting strategies. In another study [5], shorter cutting times and lower cutting forces are achieved with selection of optimal feed rate values when machining aluminum mold geometry of a bottle. The authors achieved an improvement of $13 \%$ in cutting time and a decrease of $70 \%$ in maximum forces in finish cutting operations. The tool paths directly affect finish part quality [6] and machining time [7]. As well-known, possible toolpaths and collision scenarios between cutting tool and workpiece can be checked in CAD/CAM software, thus, potential additional time and costs can be prevented. An optimization study on CNC face milling operation of an aluminum flange (Al-6061-T6) was performed by Jarosz et al. [8]. They found that it is possible to reduce machining time up to $37 \%$ with selection of proper optimization strategy without exceeding imposed machining parameter limits. In another study, Souza et al. [9] investigated the effects of different tool path strategies on surface roughness and machining time during finish milling of a mold cavity. The results showed that when compared to the less appropriate option, selection of an improved tool path strategy can decrease the machining time and machining costs by $88 \%$ and $40 \%$, respectively.

Literature survey showed that it is possible to significantly increase the productivity with improvement of machining processes using different strategies. In this study, improvement of machining processes of a boom-body connector which is a component (GGG 40) of a backhoe loader manufactured by Pi Makina [10] was performed. This component has 22 different machining operations such as turning, milling, drilling, boring, and tapping. Firstly, present machining strategy of the component was analyzed. Then, some improvements on casting geometry, machining operation orders, and cutting conditions were performed. Tool paths were regenerated for each condition with the aid of a MasterCAM software and cutting parameters were determined. As a result, when compared with initial machining strategy, a decrease by about $55 \%$ in machining time was achieved and thus, productivity increased.

\section{Materials and Method}

After examination of process plan of boom-body connector, it is determined that there are 22 different machining operations. In addition, current fixture design for CNC bohrwerk and existing limitations were analyzed. Then, 3D CAD model of the boom-body connector was prepared in accordance with the cast product. Thus, improvement studies of the cast model and tool paths were performed on this model. Tool path improvements were performed with the aid of MasterCAM software [11]. Each machining operation was simulated, and the improved machining time was determined according to simulation results. In addition, possible collision scenarios between tool and workpiece were checked. Then, a boom-body connector was machined under improved conditions. The real machining time of improved operations was determined and correlated with simulation results. Figure 1 indicates an example for simulation of a milling operation. During the improvement stages, to avoid wasting time between the successive operations, the order of the required machining operations was rearranged. 


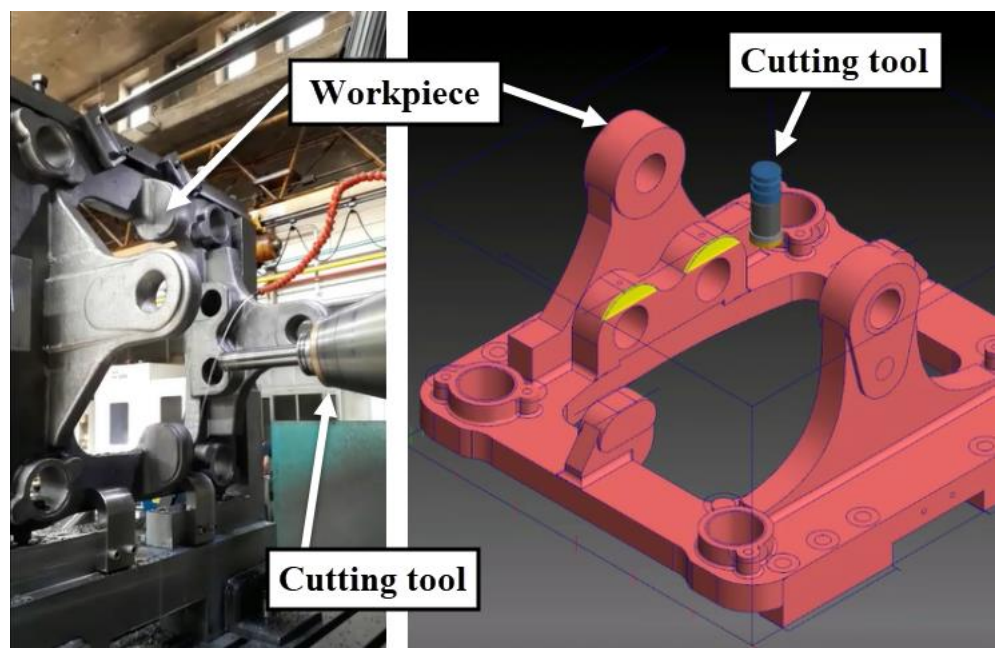

Figure 1. An example for a CAM simulation.

After determination of the optimal machining orders, cutting parameters (cutting speed, feed, and depth of cut) were rearranged according to tool manufacturers recommendations and some limitations such as vibration and workpiece clamping conditions. In addition, cutting tools for some operations were also revised. The surface roughness and machining tolerances were accepted as success criterion for each machining operation. Figure 2 gives the flow chart of the improvement process in this study.

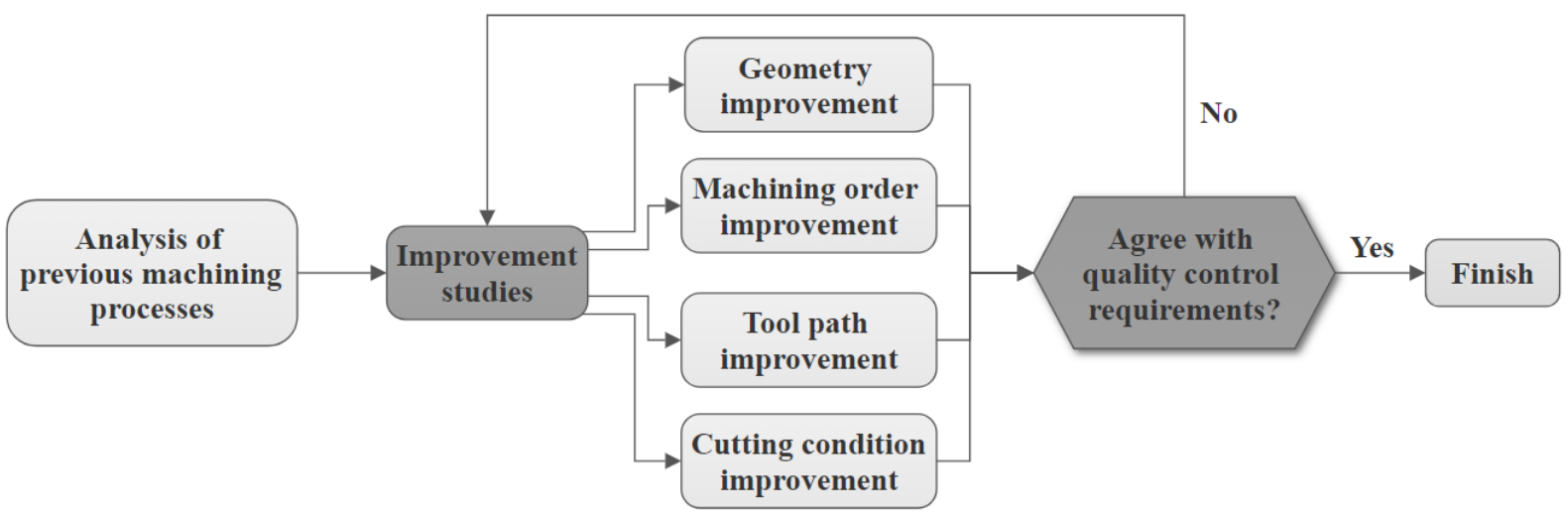

Figure 2. The improvement process.

\section{Results and Discussion}

\subsection{Improvements on cast geometry and cutting method}

As a first stage of the improvement studies, possible improvements on casting geometry was investigated to reduce the number of machining operations. Figure 3 shows the cast geometry before and after improvement. With adding two new holes on cast geometry (Figure 3), a drilling operation (operation 2 in Figure 5) was eliminated. Thus, when considering the set up and 
machining time, a reduction of $60 \mathrm{~min}$ in total operation time was achieved.
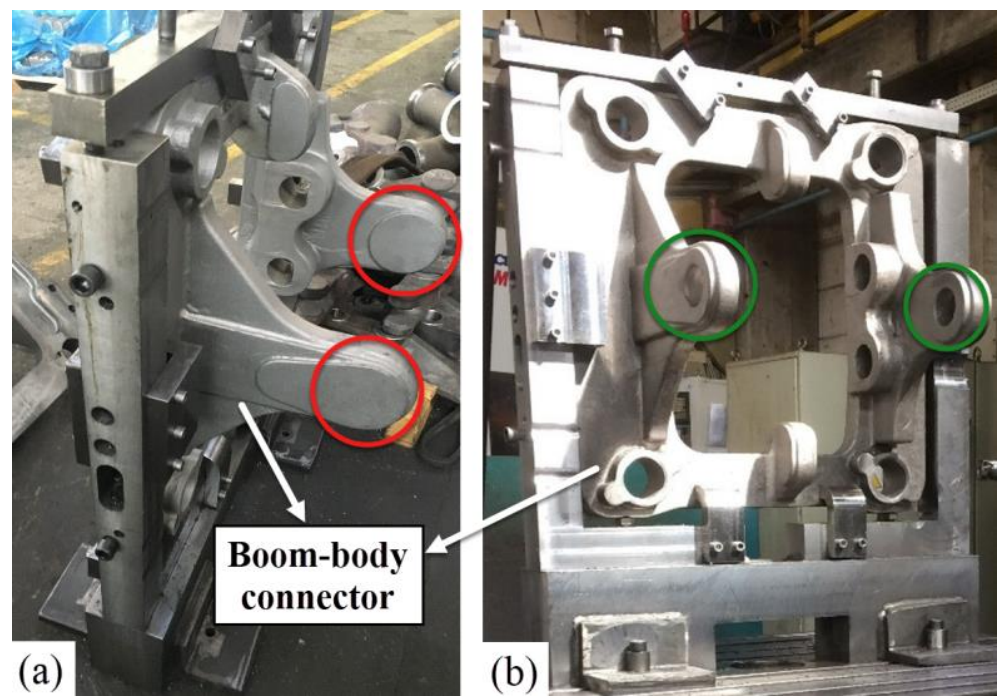

Figure 3. The pictures of the boom-body connector a) before and b) after improvement on casting geometry.

In addition to improvements on casting geometry, an improvement was also conducted on cutting methods. Figure 4 indicates an example (operation 9) for cutting method improvement. As shown in Fig. 4, new cutting method is end milling while previous cutting method for operation 9 is fly cutting. End milling and its tool path is simpler and more effective than fly cutting. The significant reductions in setup and machining time were achieved with new cutting method for operation 9. Besides, better surface quality and higher cutting parameters (Table 2) were also achieved with new cutting method.
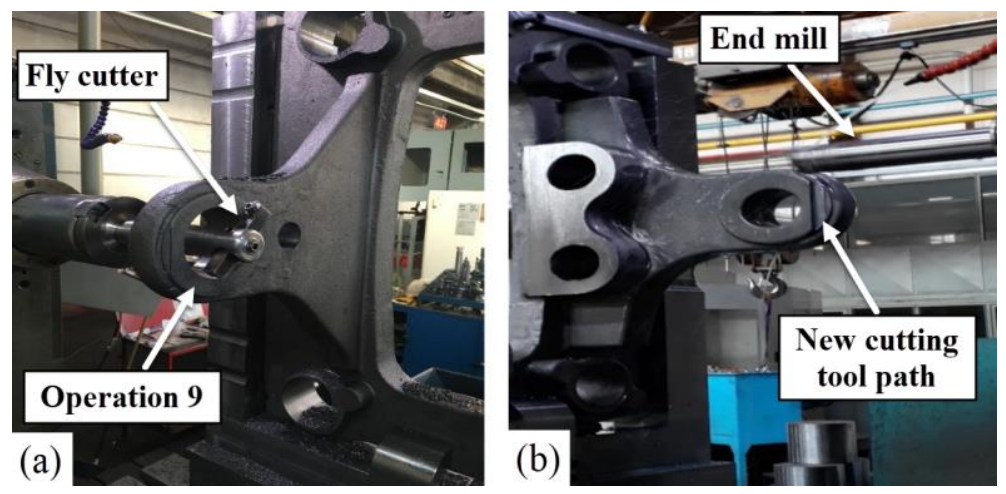

Figure 4. The pictures of operation 9 a) before and b) after optimization of cutting method.

\subsection{Improvements on machining order}

In order to decrease machining time, previously determined machining orders were rearranged according to tool path simulation results and tool change order. Thus, minimum setup time was obtained for each machining condition. Table 1 gives the all the machining operations of the boom- 
body connector (Figure 4) and previous and improved operation orders.

Table 1. Rearrangement of machining orders.

\begin{tabular}{ccc}
\hline Machining operation & $\begin{array}{c}\text { Previous } \\
\text { operation order }\end{array}$ & $\begin{array}{c}\text { New operation } \\
\text { order }\end{array}$ \\
\hline Face milling & 5 & 1 \\
Face milling & 7 & 2 \\
Face milling & 4 & 3 \\
Face milling & 9 & 4 \\
Face milling & 11 & 5 \\
Face milling & 8 & 6 \\
Boring - Ø85 rough machining & 13 & 7 \\
Boring - Ø85 finish machining & 14 & 8 \\
Boring - Ø80 rough machining & 15 & 9 \\
Boring - Ø80 finish machining & 16 & 10 \\
Boring - Ø92 rough machining & 1 & 11 \\
Boring - Ø92 finish machining & 12 & 12 \\
Groove milling - Ø83.5 & 17 & 13 \\
Peck drilling - Ø38 & 3 & 14 \\
Peck drilling - Ø14 & 18 & 15 \\
Tapping - M16 & 19 & 16 \\
Peck drilling - Ø25 & 6 & 17 \\
Face milling & 10 & 18 \\
Drilling - Ø9 & 22 & 19 \\
Drilling - Ø22.5 & 20 & 20 \\
Drilling - Ø8.5 & 21 & 21 \\
Drilling & 2 & Eliminated \\
\hline
\end{tabular}

New operation orders were determined by successively rearranging the same type machining operations used same cutting tool. A reduction of about $30 \%$ (from $365 \mathrm{~min}$ to $254 \mathrm{~min}$ ) in set up time was achieved with new machining orders. Figure 4 shows 3D CAD model of the boom-body connector and its machining operations and orders before (black numbers) and after (red numbers) improvement process. Red and blue areas indicate the machined surfaces of the boom-body connector.
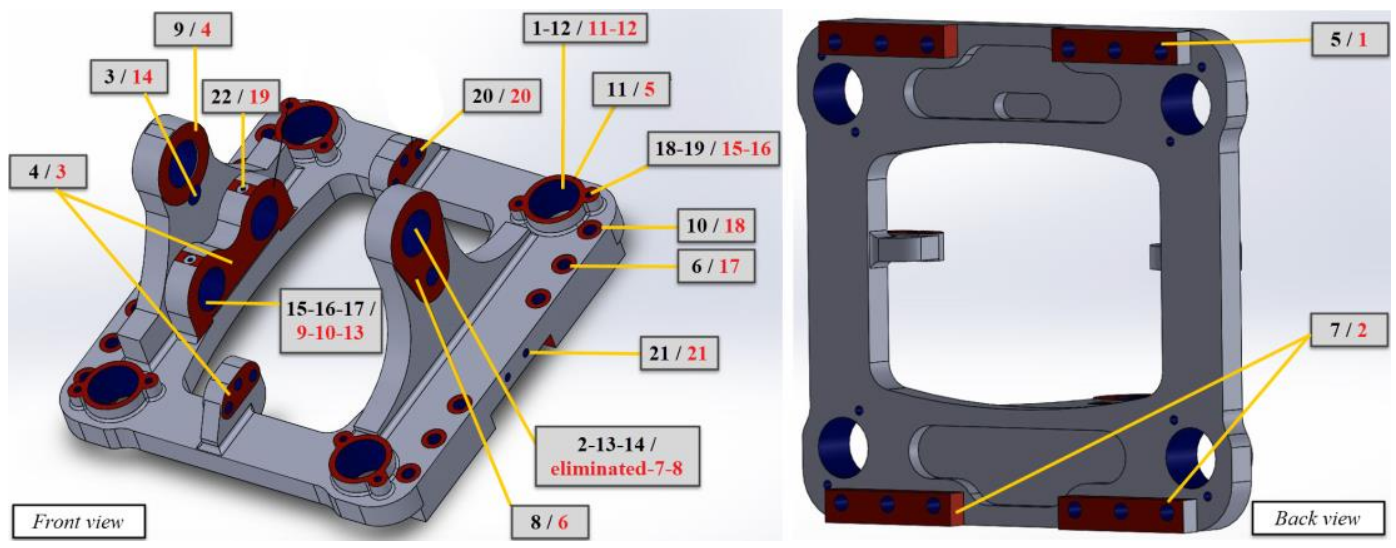

Figure 5. Machining operations on 3D CAD model of boom-body connector and their orders before and after improvement process. 


\subsection{Improvements on cutting conditions}

After rearrangement of machining orders, some improvements on cutting conditions (cutting speed, feed rate, and depth of cut) in some operations were performed. Table 2 indicates the cutting conditions before and after the improvement process.

Table 2. Improvement of cutting parameters.

\begin{tabular}{ccccccc}
\hline \multirow{2}{*}{$\begin{array}{c}\text { Operation order } \\
\text { (improved })\end{array}$} & \multicolumn{3}{c}{ Previous cutting conditions } & \multicolumn{3}{c}{ Improved cutting conditions } \\
\cline { 2 - 7 } & $\begin{array}{c}\text { Cutting speed } \\
(\mathrm{m} / \mathrm{min})\end{array}$ & $\begin{array}{c}\text { Feed rate } \\
(\mathrm{mm} / \mathrm{min})\end{array}$ & $\begin{array}{c}\text { Depth of } \\
\text { cut }(\mathrm{mm})\end{array}$ & $\begin{array}{c}\text { Cutting speed } \\
(\mathrm{m} / \mathrm{min})\end{array}$ & $\begin{array}{c}\text { Feed rate } \\
(\mathrm{mm} / \mathrm{min})\end{array}$ & $\begin{array}{c}\text { Depth of } \\
\text { cut }(\mathrm{mm})\end{array}$ \\
\hline 1 & 102 & 590 & 1 & 110 & 850 & $1.5 / 1$ \\
2 & 102 & 590 & 2 & 122 & 935 & $3 / 0.5$ \\
3 & 102 & 590 & 1.5 & 112.3 & 1020 & $2.5 / 1.5$ \\
4 & 102 & 590 & 0.25 & 112.3 & 1020 & 2 \\
5 & 102 & 590 & 0.5 & 108.4 & 750 & 1 \\
6 & 102 & 590 & 0.5 & 102.1 & 825 & 0.5 \\
7 & 67.5 & 20 & 1 & 102.1 & 825 & 1 \\
8 & 26.7 & 20 & 0.5 & 40 & 300 & 0.5 \\
9 & 105.4 & 30 & 1 & 159.3 & 590 & 1 \\
10 & 25 & 25 & 0.5 & 37.7 & 30 & 0.5 \\
11 & 123 & 30 & 1 & 185.8 & 590 & 0.5 \\
12 & 43.4 & 20 & 1 & 86.7 & 25 & 0.5 \\
13 & 85.1 & 100 & 2 & 85.1 & 100 & 2 \\
14 & 51.3 & 20 & 1 & 51.3 & 30 & 2 \\
15 & 19 & 15 & 1 & 22.7 & 30 & 4 \\
16 & 5 & 15 & 1 & 10 & 30 & 3 \\
17 & 33.8 & 15 & 1 & 35.3 & 30 & 3 \\
18 & 67.5 & 30 & 1 & 67.5 & 30 & 2 \\
19 & 12.7 & 30 & 30 & 15.5 & 90 & 30 \\
20 & 7 & 15 & 41 & 10.6 & 20 & 41 \\
21 & 11.5 & 30 & 15 & 12 & 70 & 15 \\
22 & 101.5 & 15 & & & Eliminated & \\
\hline
\end{tabular}

According to the improved cutting conditions, new machining time for each machining operation was determined. The machining time before and after improvement studies is given in Figure 6. A significant reduction was achieved in operation 1 with increasing cutting speed, feed values. In addition, depth of cut value was increased 1.5 times for rough machining. This strategy was also applied to operation 2 (from 0.5 to 3 ). In operation 3 , considering the clamping conditions depth of cut value was increased from 1.5 to $2.5 \mathrm{~mm}$ for down milling. In the successive operations, only cutting conditions and tool paths were improved. Generally, in all operations, cutting parameters were increased, thus an important improvement was achieved in machining time. In face milling operations (the operations from 1 to 6), the feed rate values were increased and cutting speeds kept almost as it is when compared to previous values. In majority of the rough and finish boring operations, feed rate increased significantly and depth of cut values decreased in some operations (operations 11 and 12) to provide rigid machining conditions. On the other hand, in drilling and tapping operations due to lesser material removal rate and narrow machining parameters range, lesser increase in productivity was observed generally. Since the number of holes (12 holes) to be drilled is higher, the most reduction in machining time was observed in operation 17 among the 
other drilling operations. In some operations (operation 13), due to surface quality requirements, cutting parameters were used as it is. When compared to the previous conditions, a reduction of about 55\% (from $1013 \mathrm{~min}$ to $458 \mathrm{~min}$ ) is achieved in machining time. It was observed that to keep machining time and cost low, the most effective cutting parameter is depth of cut.

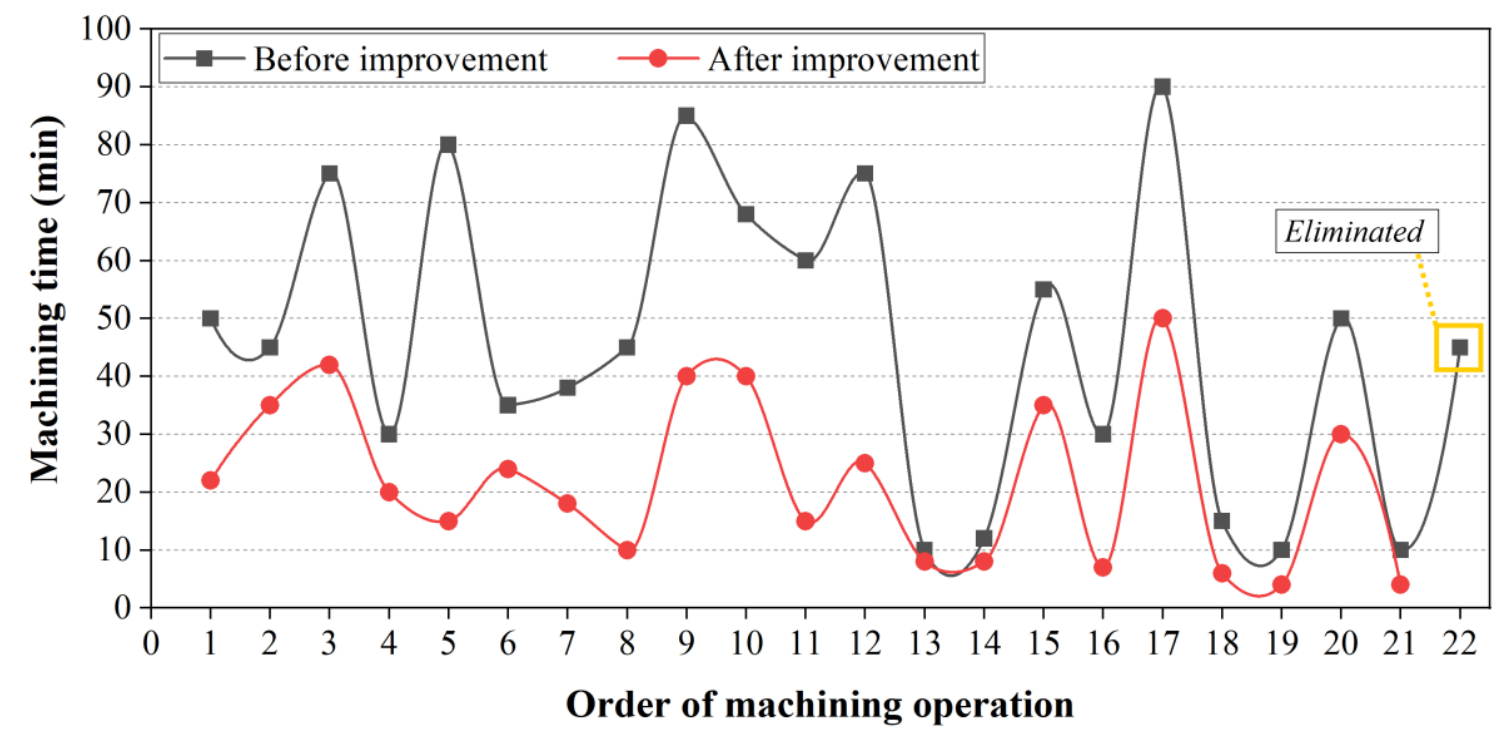

Figure 6. Machining time for each machining operation before and after improvement process.

\section{Conclusions}

In this study, an improvement process was conducted in machining process of a boom-body connecter which is a component of a backhoe loader. The results of the study showed that improvements on casting geometry, cutting method and conditions and machining order significantly affect the machining time and productivity. According to improvement results, reductions in setup time and machining time are by about $30 \%$ and $55 \%$, respectively. It can be concluded that improvement of machining strategies for complex parts has a considerable impact on productivity.

\section{Acknowledgements}

This work was supported by The Scientific and Technological Research Council of Turkey (TÜBİTAK-BİDEB-2209B), Project number: 1139B411702349. The authors thank to TUBİTAK for the financial support.

\section{References}

[1] Groover MP, Fundamentals of Modern Manufacturing: Materials, Processes, and Systems, 4th ed. New York, ABD: John Wiley \& Sons; 2013. 
[2] Yusup N, Zain AM, Hashim SZM. Evolutionary techniques in optimizing machining parameters: Review and recent applications (2007-2011). Expert Systems with Applications 2012;39(10):9909-27.

[3] Baskar N, Asokan P, Prabhaharan G, Saravanan R. Optimization of machining parameters for milling operations using non-conventional methods. Int. J. Adv. Manuf. Technol 2005;25(11-12):1078-88.

[4] Rodriguez-Alabanda O, Bonilla M, Guerrero-Vaca G, Romero P. Selection of parameters and strategies to reduce energy consumption and improve surface quality in EN-AW 7075 molds machining. Metals 2018; 8(9):688.

[5] Jerard RB, Fussell BK, Hemmett JG, Ercan MT, "Toolpath feedrate optimization: A case study. Proc. 2000 NSF Design \& Manufacturing Research Conference, ancouver, British Columbia, Canada 2000; 3-6.

[6] Gologlu C, Sakarya N. The effects of cutter path strategies on surface roughness of pocket milling of 1.2738 steel based on Taguchi method. J. Mater. Process. Technol. 2008;206(13):7-15.

[7] Sales HR, Amirabadi H., Hosseinabadi HN, Bagheri MR, Experimental study of tool path strategies for three and five axes milling along with feed rate optimization, Indian J. Sci. Technol. 2016;9(43):1-12.

[8] Jarosz K, Löschner P, Nieslony P, Krolczyk G, Optimization of CNC face milling process of Al-6061-T6 aluminum alloy. Journal of Machine Engineering 2017;17(1), 69-77.

[9] Souza AF, Machado A, Beckert SF, Diniz AE. Evaluating the roughness according to the tool path strategy when milling free form surfaces for mold application. Procedia CIRP 2014;14:188-93.

[10] “Pi makina-1." [Online]. Available: https://pimakina.com.tr/is-makinasi. 19 October 2019.

[11] MasterCAM.2018. CNC Software, Inc., Tolland, Connecticut, US. 